\title{
Evaluation of Evaporative Heat Transfer Characteristics of Helmets
}

\author{
Xiaoxiong $\mathrm{Liu}^{1)}$ and Ingvar Holmér ${ }^{2)}$ \\ 1) Divison of Industrial Ergonomics, Luled, University of Technology, S-971 87 Luled, Sweden \\ 2) Department of Ergonomics, National Institute for Working Life, S-171 84 Solna, Sweden
}

\begin{abstract}
The prime purpose of a safety helmet is to protect against occupational hazards. However, thermal comfort is one important ergonomics requirement for a helmet to be accepted by its wearer. To design and manufacture a thermally comfortable helmet, a method for testing and evaluating the thermal properties is essential. Research has long focused on the evaluation of dry heat transfer (conduction, convection and radiation). Evaporative heat transfer was not much addressed. In order to analyze the wet heat transfer (evaporation) component, a sweating thermal head manikin has been used. In this study the method has been further improved by constructing a new sweating head manikin. The surface of the head manikin is divided into five zones which can provide more detailed information about the environmental effects on the heat transfer from the head when a helmet is worn. Water supply (simulated sweating) is also improved by use of an electronic pumping system which provides a steady and adjustable flow rate of water to the head manikin. Experiments were conducted within a climatic chamber with this improved method under different test conditions: the ambient temperature and the head manikin surface temperature are set at the same level: $34 \pm 0.5^{\circ} \mathrm{C}$; two levels of head surface wettedness: 0.44 and 1.0 ; two levels of ambient humidity: $30 \%$ and $60 \%$; and two levels of wind speed: $0.4 \mathrm{~m} / \mathrm{s}$ and $1.0 \mathrm{~m} / \mathrm{s}$. Seven different helmets were used in the experiments. The results showed that the improved method revealed more detailed information about the evaporative heat transfer; it is easier to use and control; less error is involved with the measurement.
\end{abstract}

(Appl Human Sci, 16 (3): 107-113, 1997)

Keywords: method, evaporative heat transfer, sweating manikin, thermal comfort, helmet, personal protective equipment

\section{Introduction}

Thermal comfort is an important wearability need of a helmet in order for it to be accepted by its wearers. The manufacturers of helmets are strictly guided by the protection performance requirements as stipulated in available standards. While the methods used to test the protection needs of a helmet have been widely studied, refined and included in the respective standards, methods for testing the thermal transfer properties of a helmet are lacking. For many years, research has been concentrated on the evaluation of the dry heat transfer (conduction, convection and radiation) component. In recent years, sweating manikins have been developed in environmental physiological studies. The existing sweating manikins are capable of simulating human sweating in the trunk, arms and legs under controlled conditions, but simulation of sweating in the faces, hands and feet have not been fulfilled yet.

To evaluate experimentally the wet heat transfer (evaporation) component, a method was developed in our earlier study (Liu and Holmér, 1995) to simulate sweating of a human head on a thermal head manikin and to test the wet heat transfer of different helmets. This method has been used in a series of experiments in a climatic chamber, where different helmets were used. The results from these tests revealed relevant information about the evaporative heat transfer properties for different helmets. This method has been further improved now and extensive experimental tests were conducted to verify the improvements.

\section{Method}

\section{The new manikin head}

A new manikin head has been designed and constructed (see Fig. 1). The head manikin is made of polyester by casting the polyester foam into a pre-made mold. The whole manikin head surface is divided into five different zones: the skull, forehead, face, ears and the 


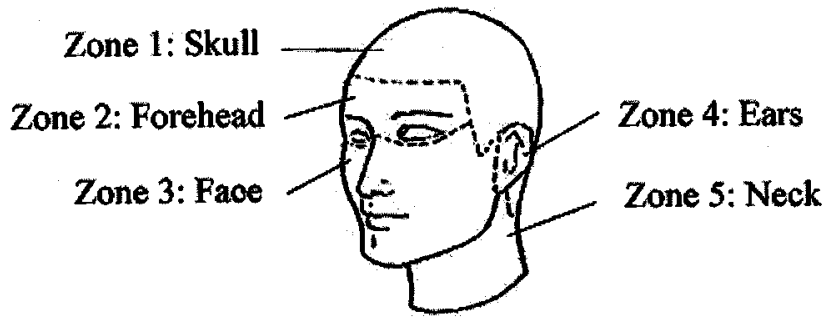

Fig. 1 The head manikin

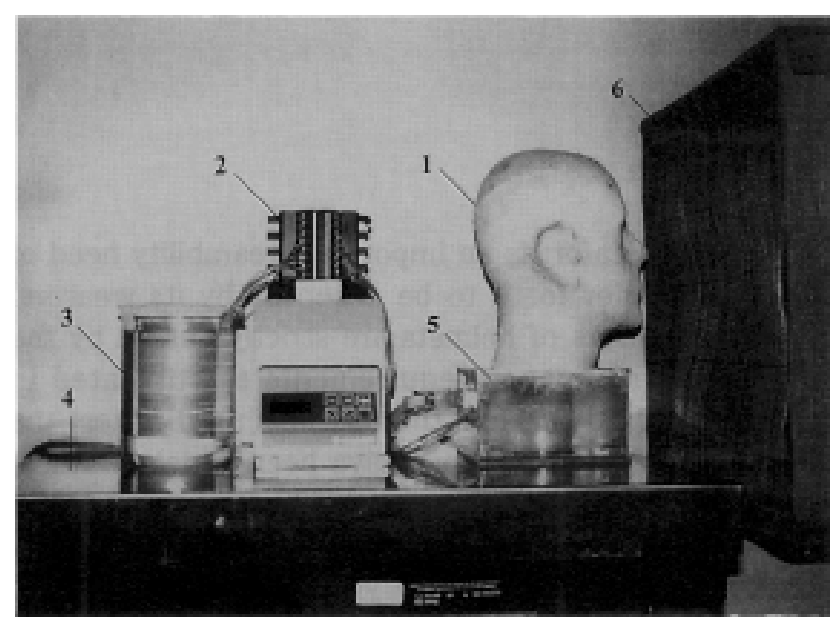

Fig. 2 The experimental system

1. The sweating head manikin;

2. The pumping system (Gilson Minipuls 3);

3. Water reservoir (covered during experiments);

4. Weighing machine (KC240);

5. Closed box;

6. Wind tunnel.

neck. Different heating wires (electrical resistance wires) were separately wired in the different zones and covered with a polyester layer. Measurement wires were then placed on the layer for the measurement of the mean surface temperature in each zone with a computerized control system which also controls and regulates the surface temperature of each zone to be within $34 \pm 0.1^{\circ} \mathrm{C}$ to simulate the surface temperature of a human head. Table 1 lists the main specifications of the manikin.

\section{Improvement in simulation of sweating}

Similar to the head manikin used in our earlier method, the new head manikin was covered with a cotton stocking to simulate the human 'skin'. This stocking was tightly held on the manikin surface to eliminate any air trapped in between the manikin surface and the stocking.

An electronic pumping system was used to replace the earlier water (simulated sweat) supply utility. It consists of a peristaltic pump (Gilson Minipuls 3) which is
Table 1 Data for the sweating manikin head

\begin{tabular}{lccc}
\hline Zone & Area $\left(\mathrm{m}^{2}\right)$ & $\begin{array}{c}\text { Heating Power } \\
\text { (Watt) }\end{array}$ & $\begin{array}{c}\text { Heating Wire } \\
\text { Resistance (ohm) }\end{array}$ \\
\hline Skull & 0.0616 & 24.6 & 38.3 \\
Forehead & 0.0146 & 5.8 & 161.2 \\
Faces & 0.0314 & 12.6 & 76.1 \\
Ear & 0.0087 & 3.5 & 664.7 \\
Neck & 0.0322 & 12.9 & 77.6 \\
Total & 0.1483 & 59.4 & \\
\hline
\end{tabular}

designed for transferring fluids with a high level of speed stability and a low pulsation level. Gilson Minipuls 3 is powered by a hybrid stepper-motor and controlled by an integral microprocessor by using the front-panel keypad (see Fig. 2). The pump head is composed of a rotor with idle stainless steel rollers that press a flexible piece of tubing against a cam. In this way liquids are pumped by a peristaltic effect. A pump head with eight tubings is used for the new water supply system. The five individual zones on the manikin head surface are supplied with water through five PVC peristaltic tubing $(\phi 0.32 \mathrm{~mm})$. By adjusting the cam pressure and/or the pump speed the flow rate of the water supply can be controlled. The flow rate of the water supply used in the improved method was $21 \mathrm{~g} / \mathrm{min}$ in total (the flow rates for the five tubing ranges from $0.35 \mathrm{~g} / \mathrm{min}$ to $0.45 \mathrm{~g} / \mathrm{min}$, depending on which zone the individual tubing is in).

\section{The head manikin surface wettedness control}

In order to evaluate the effects of surface wettedness on wet heat transfer and to simulated different sweating of a human head, two levels of the manikin head surface wettedness were used in the tests with the improved method: 1.0 and 0.44 . Instead of covering a perforated polyethylene film on the manikin head surface in earlier method, which was also used by other studies (T'amura and Tomizawa, 1991), surgical tape (Blenderm ${ }^{\mathrm{rM}} 3 \mathrm{M}$ ) was used to tape on the head manikin to control the surface wettedness. By controlling the openings between the taping strips, the wettedness level of 0.44 was achieved. Wettedness 1.0 was fulfilled when the head manikin was fully wetted without taping the surgical tape. The actual surface wettedness on the manikin head was determined by the following equation:

$$
w=E_{\text {measured }} / E_{\max }
$$

where $E_{\text {measured }}$ is the actual evaporative heat transfer (power consumption) measured when the surface was completely wetted and taped with the surgical tapes, and $E_{\text {max }}$ is the evaporative heat transfer measured when the surface was completely wetted without taping. The two surface wettedness levels were determined under the conditions: head manikin surface temperature $=$ ambient temperature $=34 \pm 0.5^{\circ} \mathrm{C}$, ambient relative humidity $=30 \%$. 
Water (simulated sweat) loss calculation and recording

Heat exchange by evaporation is determined by the amount of water (sweat) evaporated at the skin surface and transported as vapor to the environment. The amount of heat actually dissipated is determined by the latent head of vaporization. The heat transfer process is a mass transfer (water vapor) and is determined by the following formula (Holmér and Elnäs, 1981):

$$
E=60 W_{t} 0.68 / A_{d}\left(W / m^{2}\right)
$$

where $E$ is the evaporative heat loss, $W_{t}$ is the rate of change of body mass in $\mathrm{g} / \mathrm{min}, 0.68$ is the latent heat of sweat in Wh/g, and $A_{d}$ is the body surface area in $m^{2}$.

Thus, the rate of change of body mass can be expressed as:

$$
W_{\iota}=E A_{d} / 60 \cdot 0.68=E A_{d} / 40.8(\mathrm{~g} / \mathrm{min})
$$

Each helmet was weighed immediately before and after each test with a weighing machine (Sartorius 1403MP). The difference between the before- and aftertests was subtracted from the recorded weight loss values for the determination of the accuracy in weight loss recording. The recorded water loss in each helmet was compared with the values calculated using formula 3.

\section{The experimental system}

The experimental system used in the improved method is shown in Fig. 2. All experiments were conducted within a climatic chamber, where the ambient environments were controlled according to the requirements of each test. Since the environmental conditions (especially the ambient temperature and relative humidity) for each test were set and kept constant at least 12 hours (usually overnight) in advance of a test being carried out, it was assumed that the temperatures of the walls and the floor of the climatic chamber were the same as the ambient temperature, so the possibility of dry heat loss by radiation was eliminated.

The experimental facilities were placed on a weighing machine (KC240) to record the weight loss (water loss) from the head manikin during tests. Water was supplied from the water reservoir (a glass container) through the pumping system to the head manikin. Unlike the earlier method, where water was supplied to the head manikin from an outside piping system, five 'sweat glands' (previously there were only two) were built inside the head manikin. This new feature enabled that water can be supplied from inside the head manikin, which causes no disturbance to the water supply when a helmet worn on the head manikin. To prevent extra water loss by evaporation, the water reservoir was covered and the box under the head manikin was made air-tight. Wind was also simulated during some of the experiments by use of a wind tunnel which can provide a evenly distributed wind at a speed range of $0.2-10 \mathrm{~m} / \mathrm{s}$. During wind simulated tests, the head manikin was placed 20 centimeters in front of the wind tunnel with its nose tip pointing at the geometric center of the wind tunnel outlet.

\section{Experimental design and procedure}

A 233 factorial design was used in the experimental design to investigate the effects of ambient relative humidity, head manikin surface wettedness and wind on the evaporative heat transfer. 16 runs of different experiments were conducted in a series of tests. In order to avoid experimental errors, the order of the sixteen experiments were fully randomized, which would provide protection against the effects of lurking variables.

Experimental runs were carried out according to the pre-randomized order and followed the following procedure during the eight-and-half-hour period:

1. Primes the Gilson Minipuls 3 pump at $48 \mathrm{rpm}$ for two minutes by choosing the 'Rabbit' function on the keypad, the head manikin surface got wetted thoroughly;

2. Set the Gilson Minipuls 3 to normal operation and the head manikin was supplied with water at a flow rate of $21 \mathrm{~g} / \mathrm{min}$ for half an hour;

3. Start measurement on the nude head for one hour;

4. Continue measurements on different helmets, each for one hour until the entire experimental run finished.

The computer program was restarted when each helmet measurement began and ran for one hour to ensure that all the helmets were tested under identical conditions. Recording of the weight (water) loss on the weighing machine was also restarted for each helmet measurement.

Heat loss was measured and recorded six times per minute, the average of the heat loss taken during the last 20 minutes was used for data analysis. Weight loss recording was taken at the $30^{\text {th }}, 45^{\text {th }}$ and $60^{\text {th }}$ minute after each helmet measurement started, and the average of these three recordings was used as the weight loss in data analysis.

\section{The helmets used in the experimental runs}

Except the same five helmets which were used with the earlier method (Liu and Holmér, 1995) were used in the tests with the improved method, other two more helmets were also used. Same numbering for the helmets were used for the first five helmets: they were numbered with 1 through 5 . The other two helmets were numbered helmet 6 and helmet 7. Helmet 6 is a Swedish made plastic helmet, white in color. There are two openings in the front crown in the shell, and no chin strip is provided. Helmet 7 is a cycling helmet, also Swedish made. It is commonly used in Sweden by bicycle riders and mototrists. 

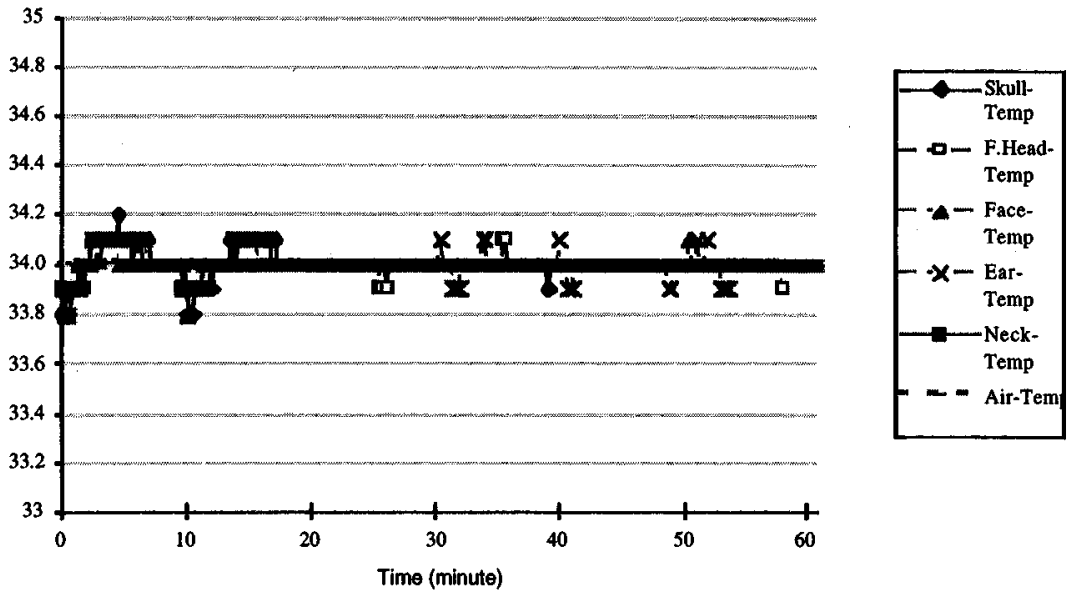

Fig. 3 Surface temperature of each zone of the head manikin during a $60 \mathrm{~min}$ measurement period.
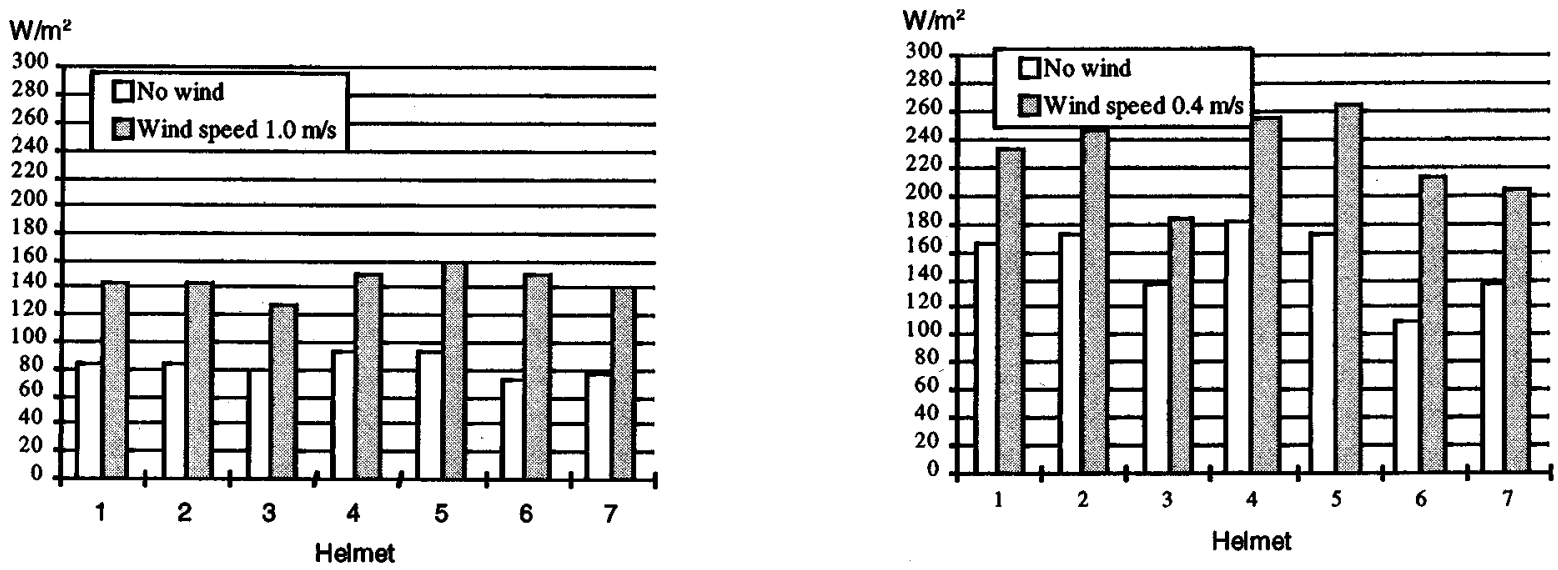

Fig. 4 Heat loss in $\mathrm{W} / \mathrm{m}^{2}$ when ambient relative humidity was $30 \%$ and wettedness was 0.44 (left) and 1.0 (right).

\section{Results}

\section{Head manikin surface temperature}

Figure 3 shows the results from one of the experiments with the head manikin. Water was continuously supplied to the head manikin during the one-hour test with each helmet. During the first 10 minutes of the hour after a helmet was put onto the head manikin, surface temperature in some zones, e.g. the skull, fluctuated within the range $34 \pm 0.2^{\circ} \mathrm{C}$. This is because the skull zone was the area which was directly affected by the wear of a helmet. From the $20^{\text {th }}$ minute surface temperature on all the five zones reached a stable value within $34 \pm 0.1^{\circ} \mathrm{C}$. This level was maintained for the rest of the time during the test. The corresponding variation in heat loss during the steady state phase was less than $5 \%$.
Heat loss when ambient relative humidity was $30 \%$ and $60 \%$

When ambient relative humidity was about $30 \%$, the heat loss from all the helmets ranged from $71 \mathrm{~W} / \mathrm{m}^{2}$ to $91.5 \mathrm{~W} / \mathrm{m}^{2}$ at the lower level of surface wettedness 0.44 , and from $108 \mathrm{~W} / \mathrm{m}^{2}$ to $179.5 \mathrm{~W} / \mathrm{m}^{2}$ when the head manikin surface wettedness was 1.0 (Fig. 4). When wind was simulated heat loss increased to the range from $125 \mathrm{~W} / \mathrm{m}^{2}$ to $156 \mathrm{~W} / \mathrm{m}^{2}$ at the wettedness level 0.44 , and to the range from $201 \mathrm{~W} / \mathrm{m}^{2}$ to $262 \mathrm{~W} / \mathrm{m}^{2}$ when the wettedness was 1.0. When the ambient relative humidity was about $60 \%$, heat loss experienced a great decrease at both wettedness levels (Fig. 5). The decrease was more than $50 \%$ no matter wind was present or not. 

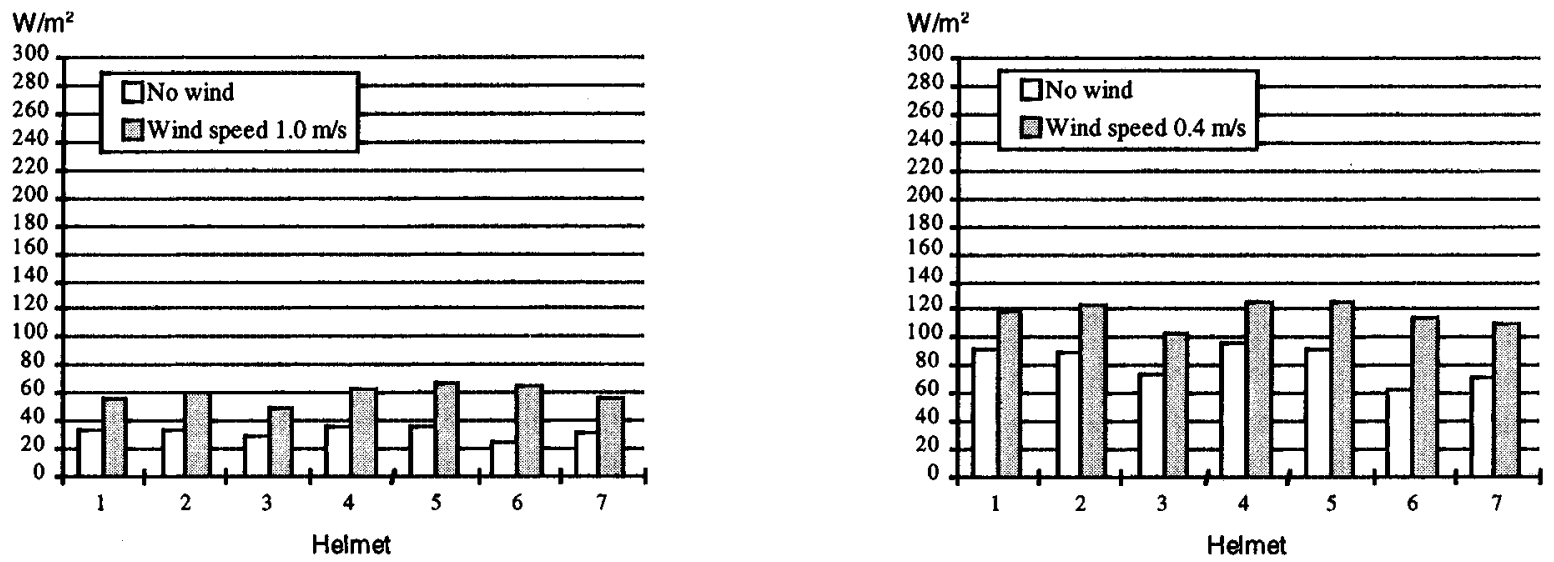

Fig. 5 Heat loss in $\mathrm{W} / \mathrm{m}^{2}$ when ambient relative humidity was $60 \%$ and wettedness 0.44 (left) and 1.0 (right)
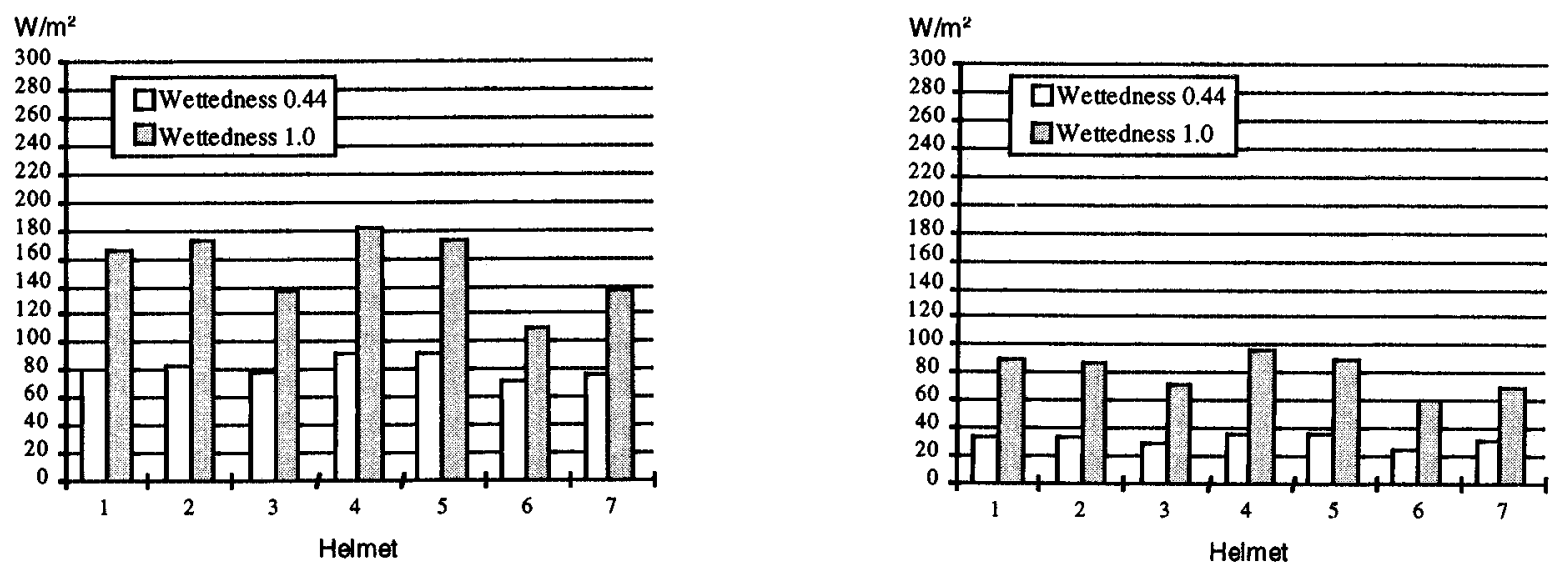

Fig. 6 Heat loss in $\mathrm{W} / \mathrm{m}^{2}$ at two surface wettedness levels in an ambient relative humidity of $30 \%$ (left) and $60 \%$ (right).

Heat loss when head manikin surface wettedness was 0.44 and 1.0

When the head manikin surface wettedness was 1.0 , heat loss increased sharply with all the helmets with both ambient relative humidity levels $30 \%$ and $60 \%$. The increase ranged from $42 \%$ to $105 \%$ when ambient relative humidity was $30 \%$ and from $130 \%$ to $167 \%$ when ambient relative humidity was $60 \%$ (Fig. 6 ).

\section{Weight loss from the helmets}

Weight loss from all the helmets were calculated as the pooled average values calculated of the recordings during the tests under different experimental conditions. Theoretical values were also calculated using formula 3 to compare with these recorded values. Generally the theoretical calculations are from $2 \%$ to $10 \%$ greater than the recorded values (Table 2 ).
Table 2 Weight (water) loss under different experimental conditions $(\mathrm{g} / \mathrm{min})$

\begin{tabular}{cccc}
\hline Helmet & Recorded & Calculated & Error (\%) \\
\hline 1 & 0.35 & 0.37 & 6 \\
2 & 0.38 & 0.40 & 5 \\
3 & 0.33 & 0.34 & 3 \\
4 & 0.42 & 0.43 & 2 \\
5 & 0.39 & 0.43 & 10 \\
6 & 0.29 & 0.29 & 0 \\
7 & 0.36 & 0.37 & 3 \\
\hline
\end{tabular}

\section{Discussions}

\section{Evaporative heat loss}

Evaporative heat loss was, as expected, dependent on the ambient relative humidity when the head manikin surface wettedness maintained at a certain level. On the 
other hand, with a constant relative humidity in the ambient air, higher simulated sweating (wettedness=1.0) gave rise to a higher heat loss.

To evaluate the pure evaporative heat transfer, heat loss from the whole head (all zones) recorded under the basic experimental conditions (without wind simulation) were averaged for each helmet as well as the nude head manikin, which are listed in Table 3 , as a percentage of heat loss for the nude head under the same basic experimental conditions. Heat loss under wind-simulated conditions are also listed in Table 3.

These percentages show the relative differences between helmets and the nude head. All the helmets transferred $50-75 \%$ of evaporative heat compared with the nude head. Helmets were ranked according to the magnitudes of the percentage of heat loss for tests under different experimental conditions. These rankings were then pooled for evaluation of the overall behavior of the helmets under various environmental conditions. The rattan knitted helmet 5 and the bamboo knitted helmet 4 are ranked number one and two among all the helmets.

\section{The effect of wind and ambient relative humidity}

Wind has a considerable effect on evaporative heat transfer for all helmets (Figs. 4 and 5). The magnitude of this effect was affected by the form of structure of the individual helmets. For example, under no wind conditions helmet 6 transferred less heat than helmet 7 . When wind was simulated, heat loss from helmet 6 surpassed helmet 7 . This is due to the differences in the structure of the two helmets. Albeit there are openings on both of the helmet shells, they functioned differently. The two openings in helmet 6 shell are positioned at the front part of the crown, and the helmet cradle is mounted in a way that a distance between helmet shell and the head is allowed, so air flow could pass with less resistance when wind is present. In helmet 7, even bigger area of openings are provided in the shell, but these openings are

Table 3 Averaged values for heat loss (\%)

\begin{tabular}{cccccc}
\hline Helmet & Static & Wind $^{1}$ & Wind $^{2}$ & Wind $^{3}$ & Ranking** \\
\hline 1 & $69^{(4)^{*}}$ & $85^{(4)}$ & $79^{(4)}$ & $82^{(5)}$ & 5 \\
2 & $70^{(3)}$ & $85^{(4)}$ & $82^{(3)}$ & $85^{(4)}$ & 3 \\
3 & $59^{(5)}$ & $75^{(7)}$ & $69^{(7)}$ & $73^{(7)}$ & 7 \\
4 & $75^{(1)}$ & $87^{(3)}$ & $84^{(1)}$ & $90^{(3)}$ & 2 \\
5 & $73^{(2)}$ & $93^{(3)}$ & $84^{(1)}$ & $95^{(1)}$ & 1 \\
6 & $50^{(7)}$ & $88^{(1)}$ & $77^{(5)}$ & $93^{(2)}$ & 4 \\
7 & $57^{(6)}$ & $83^{(2)}$ & $73^{(6)}$ & $81^{(6)}$ & 6 \\
\hline nude head & 100 & 100 & 100 & 100 &
\end{tabular}

Wind ${ }^{1}$ : relative humidity $30 \%$, wind speed $1 \mathrm{~m} / \mathrm{s}$ and wettedness 0.44 ; Wind ${ }^{2}$ : relative humidity $60 \%$, wind speed $0.4 \mathrm{~m} / \mathrm{s}$ and wettedness 1.0 ; Wind $^{3}$ : relative humidity $60 \%$, wind speed 1 $\mathrm{m} / \mathrm{s}$ and wettedness 0.44 . *Ranking in terms of magnitude of percentages; **Pooled average ranking. shielded with a dense nylon net; furthermore, this helmet is provided with no cradle, that is, the head is directly in contact with the helmet shell through a clothing strip. Such a structure in helmet 7 prevented good ventilation. For helmet 2, the holes drilled in the shell made it more porous than helmet 1 , which helped both ventilation and moisture movement. This is readily seen in Figs. 5, 6 and 7. Since helmets 4 and 5 are more air- and moisturepermeable, owing to their knitted construction, than plastic helmets $1,2,6$ and 7 , they transferred more heat. This may explain part of the wind effect.

With the increase in the ambient relative humidity, the difference between the helmets remained but the total heat loss reduced considerably (Fig. 6). It was noted that the effects of relative humidity on the heat loss was not linear: the difference rate of heat loss between 0.44 and 1.0 wettedness under $60 \%$ humidity was greater than that under $30 \%$ humidity. The reason needs further investigation.

\section{Heat loss from each zone in the head manikin}

With the division of the whole head manikin surface area into five sub-zones, the effect of wearing a helmet on the head on heat loss from the head can be easily investigated. Tests show that differences of heat loss from the face, ears, and the neck zones among the wear of different helmets was not statistically significant. This can be readily explained since they were less affected by wear of a helmet and exposed to the same environmental conditions during the same experimental run. Heat loss in the skull and forehead zones caused by wearing of different helmets are statistically significant at $95 \%$ confidence level.

\section{Reproducibility of the evaporative heat loss measurements}

Repeated measurements under the same experimental conditions were carried out on separate days to determine the measurement error of the method. The

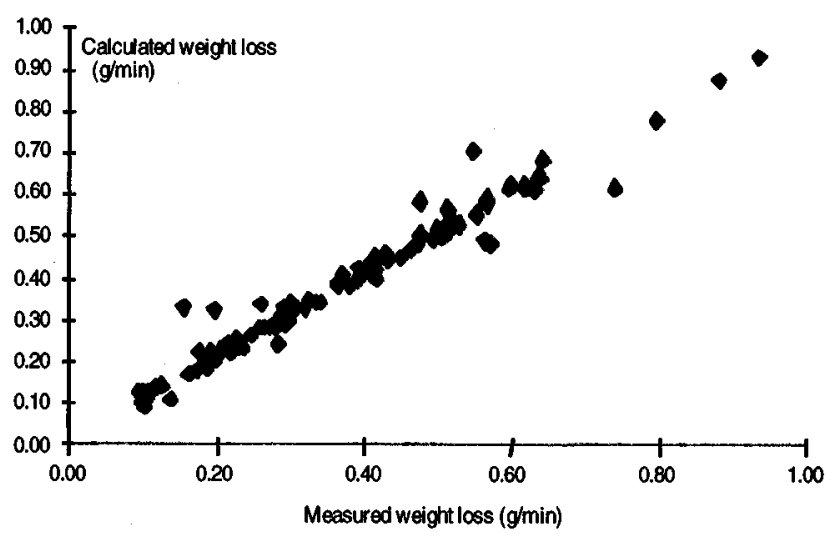

Fig. 7 Comparison of measured and calculated weight loss due to water evaporation. 
average heat loss for 24 duplicates was $107.3 \mathrm{~W} / \mathrm{m}^{2}$. The mean difference and standard deviation for the duplicates were $2.63 \pm 1.58 \mathrm{~W} / \mathrm{m}^{2}$. Statistical analysis showed that there was no significant difference between the results of the double measurements at $95 \%$ confidence level. The measurement error of the method was calculated at $3 \%$ of the mean of the double determinations. This measurement error allows differences in heat loss to be measured with sufficient accuracy. The results suggest that the improved method described in this paper is valid, reproducible and accurate enough for practical evaluation of heat transfer properties of head gear.

\section{Conclusion}

(1) The sweating head comprises an accurate and reproducible method for testing of helmet heat transfer properties as well as head heat exchange analysis;

(2) The improved method maintained the same measurement error, but is easier to use and control than the earlier method;

(3) The surface wettedness level of the head manikin as well as ambient humidity were important factors which largely determined the evaporative heat loss through the helmets;

(4) Wind simulation dramatically increased the heat loss in all helmets under various environmental conditions;

(5) Helmet structure can promote or prevent heat loss from a head, the design and construction of the cradle is critical for the success of the heat loss provided by other facilities such as openings in the helmet shell.

Acknowledgment. This study was supported by COLDTECH of Luleå University and the Swedish Council for Work Life Research. The laboratory work was carried out in the Department of Ergonomics, National Institute for Working Life (NIWL), Sweden. The authors appreciate the help from senior engineer Håkan Nilsson and researcher Kalev Kuklane at NIWL for their help during the entire laboratory work.

\section{References}

Holmér I and Elnäs S (1981) Physiological evaluation of the resistance to evaporative heat transfer by clothing. Ergonomics 24 (1): 63-74

Liu X and Holmér I (1995) Evaporative heat transfer characteristics of industrial safety helmets. Applied Ergonomics 26-2: 135-140

Tamura T and Tomizawa M (1991) Skin wettedness and evaporative heat resistance of clothing. Proceedings of $2^{\text {nd }}$ Intl. Symposium on Clothing Comfort Studies, Mt Fuji, Japan, November 1991, 23-40

Received: October 18, 1996

Accepted: March 19, 1997

Correspondence to: Ingvar Holmér, Department of Ergonomics, National Institute For Working Life, S-171 84 Solna, Sweden 